\title{
European Service Module - Structural Test Article (E-STA) Building Block Test Approach and Model Correlation Observations
}

\author{
James P. Winkel, Samantha A. Bittinger, Vicente J. Suárez, and James C. Akers \\ NASA Glenn Research Center \\ 21000 B rookpark Road \\ Cleveland, Ohio 44135
}

\begin{abstract}
The Orion European Service Module - Structural Test Article (E-STA) underwent sine vibration testing in 2016 using the Mechanical Vibration Facility (MVF) multi-axis shaker systemat NASA Glenn Research Center's (GRC) Plum Brook Station (PBS) Space Power Facility (SPF). The main objective was to verify the structural integrity of the European Service Module (ESM) under sine s weep dynamic qualification vibration testing. A secondary objective was to perform a fixed-base modal survey, while E-STA was still mounted to MVF, in order to achieve a test correlate the finite element model (FEM). To facilitate the E-STA system level correlation effort, a building block test approach was implemented. Modal tests were performed on two major subassemblies, the crew module/launch abort structure (CM/LAS) and the crew module adapter (CMA) mas s simulators. These subassembly FEMs were individually correlated and then integrated in to the E-STA FEM prior to the start of the E-STA sine vibration test. This paper summarizes the modal testing and model correlation efforts of both of these subassemblies and how the building block approach assisted in the overall correlation of the E-STA FEM. This paper will also cover modeling practices that should be avoided, recommended instrumentation positioning on complex structures, and the importance of the FEM geometrically matching CAD in sufficient detail in order to adequately replic ate internal load paths. The goal of this paper is to inform the reader of the hard earned lessons learned and pitfalls to avoid when applying a building block testapproach.
\end{abstract}

Keywords: finite element correlation, finite element modeling, modal testing, building block approach, modal testing, baseshake, environmental testing

\section{INTRODUCTION}

The Orion Multi-Purpose Crew Vehicle (MPCV), shown in detail in Fig 1, is the spacecraft that NASA is developing to send humans and cargo into space, beyond low earth orbit, and to return them safely to earth. The MPCV configuration can be broken down into the following major subassemblies which include (listed from top to bottom):

- Launch Abort System(LAS)

- Crew Module (CM) with its MPCV-ESM interface Crew Module Adapter(CMA)

- European Service Module (ESM)

- Spacecraft Adapter Jettisoned (SAJ or Fairing)

- Spacecraft Adapter(SA) 


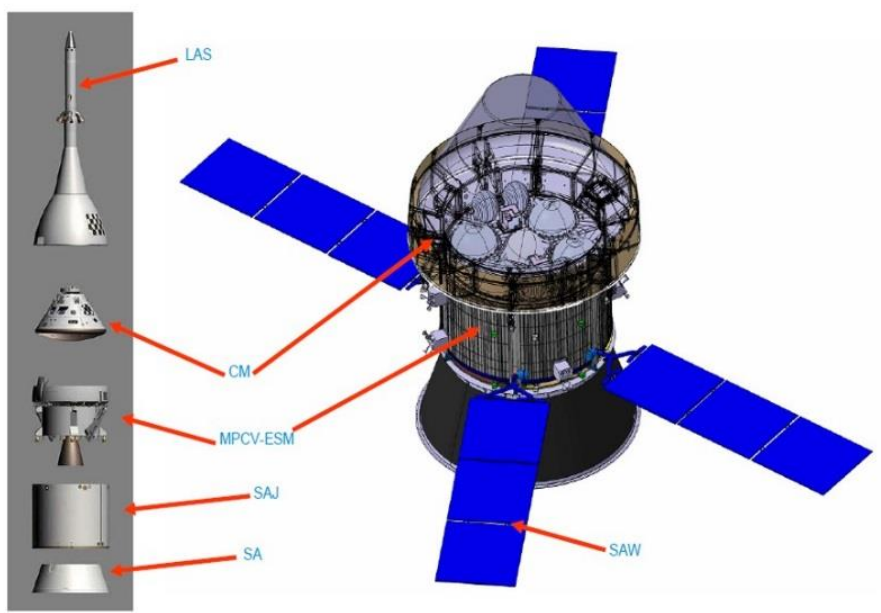

Fig 1 Multi-Purpose Crew Vehicle

The ESM - Structural Test Article (E-STA) is the term used to designate the structural mock-up of the MPCV stack that underwent acoustic and sine vibration testing at the Space Power Facility (SPF) in the Reverberant Acoustic Test Facility (RATF) and the Mechanical Vibration Facility (MVF), respectively. Both RATF and MVF are located at the NASA Glenn Research Center, PlumBrook Station, in Sandusky, Ohio. The overall layout of SPF is shown in Fig 2. The E-STA hard ware was received in pieces into the Assembly Highbay, where it was as sembled, and then transferred via rail cart to the RATF and MVF for environmental testing.

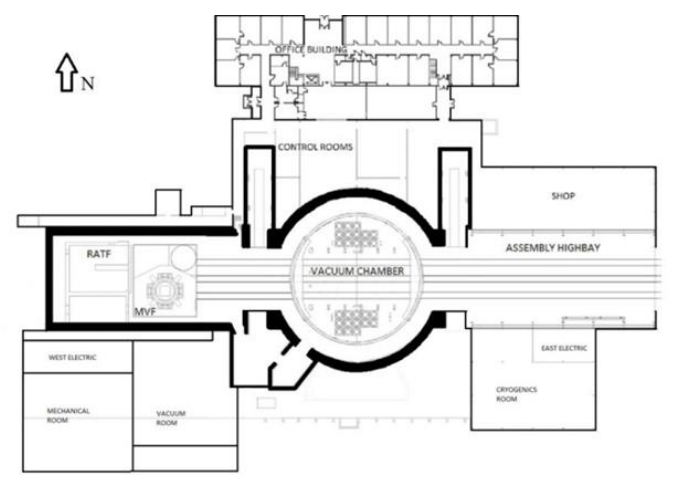

Fig 2 Space Power Facility (SPF) Overall Layout

The E-STA has a near flight-specimen of theESM hardware that is mas s loaded by a mass simulator of the CMA subassembly and CM/LAS subassembly. It also utilized well characterized versions of the SA and SAJ subsystems from the Exploration Flight Test-1 (EFT-1). The E-STA subassemblies and the testing they underwent prior to integration into the overall as sembly is shown in Fig 3. 


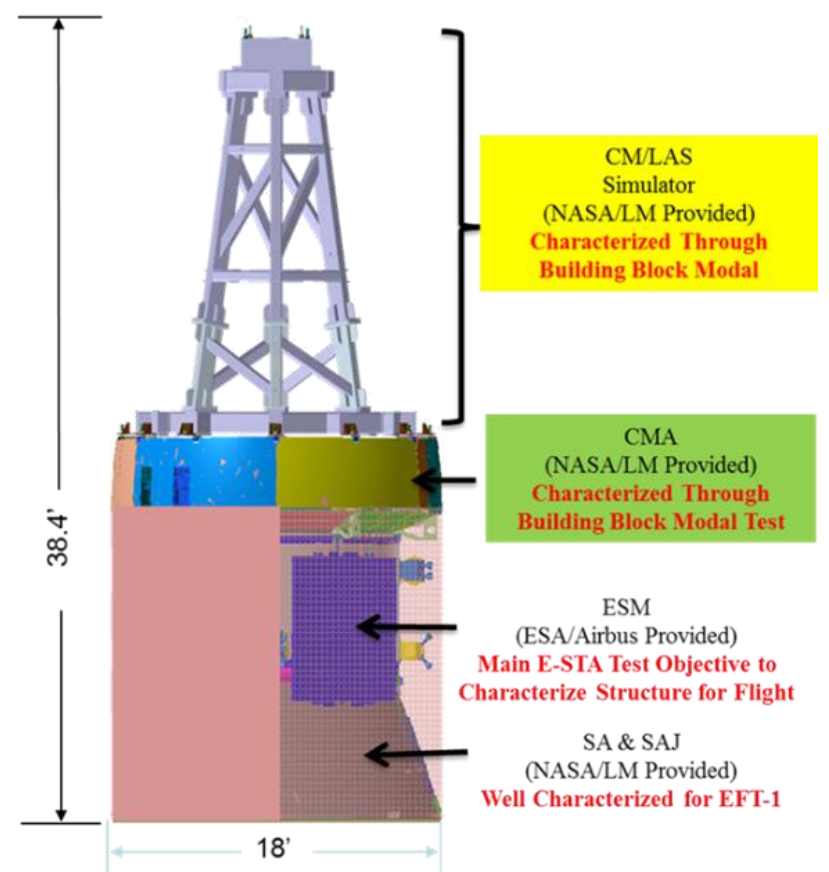

Fig 3 ESM - Structural Test Article (E-STA)

\section{BUILDING BLOCK MODAL TEST APPROACH}

In support of the following E-STA test objective: "Identify the modal parameters (frequency, mode shape and damping) for the primary modes of the E-STA and identify possible modal nonlinearities and resulting dynamic behavior", a "Building Block" modal testing approach was proposed to correlate the CM/LAS and CMA mas s simulators prior to integration.

The "Building Block" Modal Test Approach consists of testing and model correlation of individual simulators allowing engineers the ability to more accurately predict the responses of E-STA to the sine vibration testing and to make E-STA correlation more manageable by allowing test engineers to focus primarily on updating the following:

- Interface stiffness between: CM/LAS - CMA, CMA - ESM, ESM - SA, and CMA - SAJ (NASA Major Focus)

- ESM internal components (ESA/Airbus Major Focus)

The E-STA FEM prior to the start of the sine vibration testing consisted of test correlatedFEM's of the:

- CM/LAS Simulator (Modal Test at SPF)

- CMA Simulator(ModalTest at SPF

- SA Simulators (EFT-1 Heritage)

- SAJ Simulators (EFT-1 Heritage)

- $\quad$ ESM (Static Stiffness Testing) 


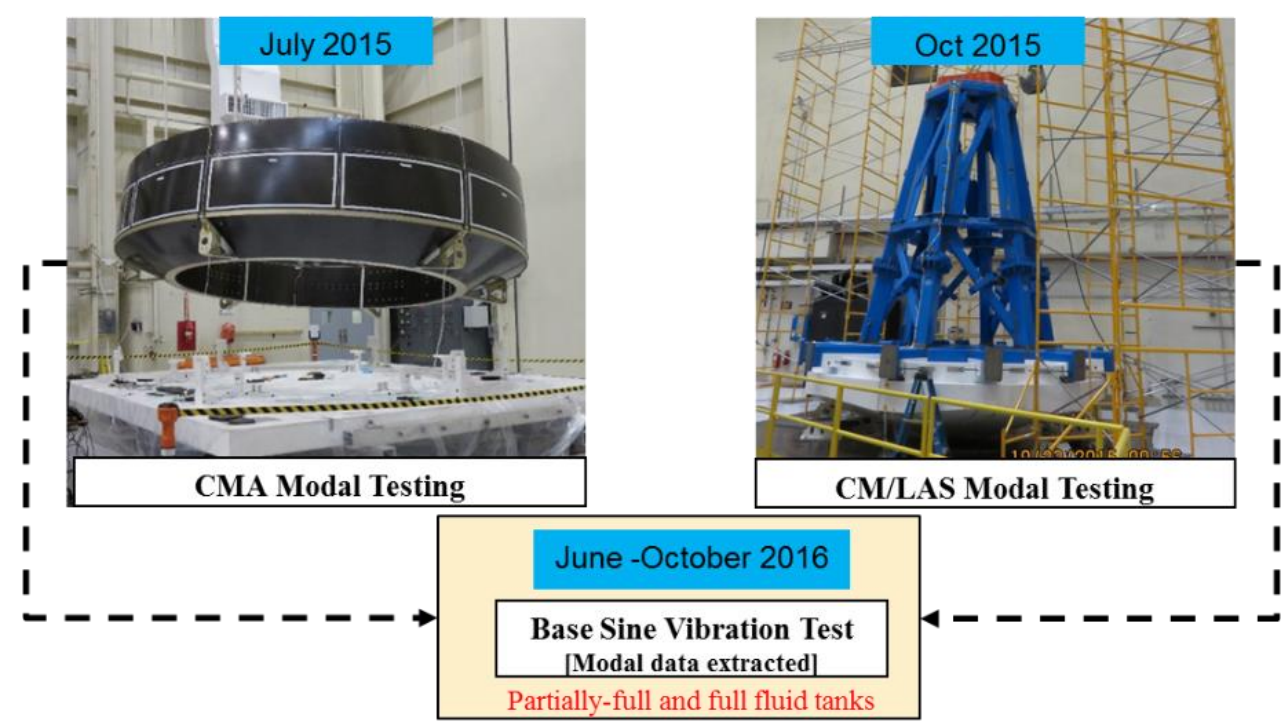

Fig 4 CMA and CM/LAS Building Block Modal Tests

\section{CREW MODULE ADAPTER (CMA) MASS SIMULATOR MODAL TEST}

The CMA connects the CM to the ESM. For the building block approach, the CMA mass simulator consisted of aluminum framing with composite panels attached. Large internal avionic mass simulators attached to the interior of the compositepanels in several locations.

A fixed-base modal survey of the CMA mass simulator with its CM/CMA interfaces mass loaded would have been preferred due to its ability to better represent the dynamic characteris tics of the load paths when integrated into E-STA. However, a fixed-base modal survey was not possible because there was no way of constraining the CMA/ESM interface due to this interface not being drilled until the CMA was integrated on top of the ESM, which had to be match drilled.

Instead, a free-free modal survey of the CMA mass simulator was performed where the free-free boundary condition was simulated by suspending CMA mass simulator on 1" thick bungee cords. The objective of this CMA mass simulator modal test was to identify the first five flexible (elastic) body modes, lis ted in Table 1. The highest frequency suspension mode was experimentally determined to be $\sim 1.0 \mathrm{~Hz}$, which was sufficiently low that it did not couple with or impact the CMA simulator target modes. This free-free modal test was conducted in the SPF as sembly highbay and is shown in Figure 5.

\begin{tabular}{|c|c|c|c|}
\hline & Mode \# & Frequency & Mode Description (1005 Coordinate System) \\
\hline & 1 & 0.00 & Rigid Body Mode 1 \\
\hline & 2 & 0.00 & Rigid Body Mode 2 \\
\hline & 3 & 0.00 & Rigid Body Mode 3 \\
\hline & 4 & 0.61 & Rigid Body Mode 4 \\
\hline & 5 & 0.77 & Rigid Body Mode 5 \\
\hline & 6 & 0.81 & Rigid Body Mode 6 \\
\hline \multirow{5}{*}{$\begin{array}{l}\text { Target } \\
\text { Modes }\end{array}$} & 7 & 22.52 & Squeeze Mode aligned with to $R$ and $\theta$ Axis \\
\hline & 8 & 25.14 & Squeeze Mode aligned with 60 Degrees \\
\hline & 9 & 31.87 & Potato Chip Mode aligned with to $R$ and $\theta$ Axis \\
\hline & 10 & 35.20 & Potato Chip Mode aligned with 60 Degrees \\
\hline & 11 & 41.04 & Tri-Lobe Ovaling Mode \\
\hline
\end{tabular}

Table 1 Target Modes 


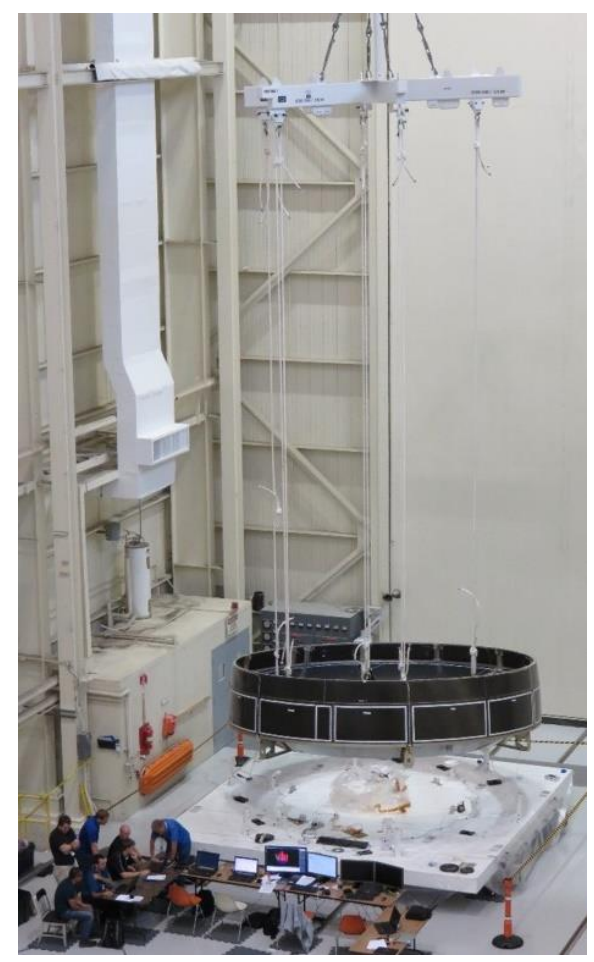

Fig 5 CMA Simulator Modal Test Setup

Table 2 shows the cross-orthogonality (x-ortho) comparison between the test TAM and the FEM. This table shows that the selected 52 DoF selected created a robust enough reduced mass matrix to capture the desired target mode shapes and will adequately support a model correlation effort.

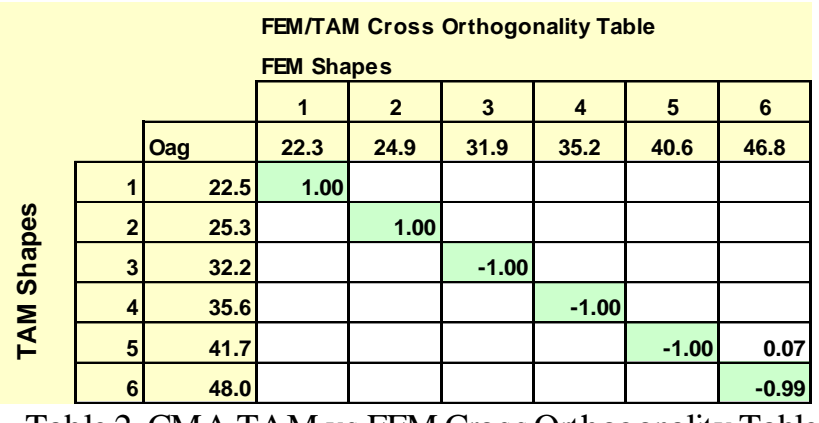

Table 2 CMA TAM vs FEM Cross Orthogonality Table

Impact hammer testing along with multi-shaker testing was utilized to excite the CMA mass simulator. The multi-shaker testing was performed using both broadband randomexcitation and sine s weep excitation. In Fig 6, one of the impact hammer drive point locations and multi-s haker layouts are shown. 

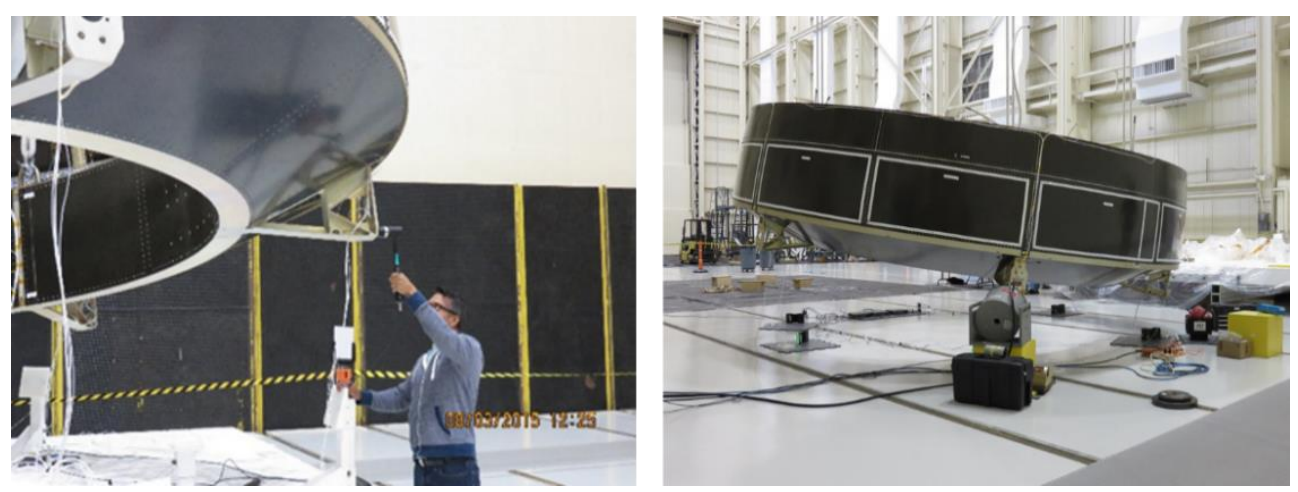

Fig 6 CMA Simulator Test Setups: Impact Hammer(left) - Multi-Shaker Setup (right)

Modes were extracted fromall runs. The mode shapes were of high quality and were invariant fromrun to run. Based on the modal parameter data, it was decided to use the single point impact method as the final technique for modal extraction due to the simplicity of the test setup. Table 3 lis ts the extracted modes that most closely matched the FEM target mode set. Modes 4 and 5 showed to be identical, and it is believed that more ins trumentation on the composite panels or accelerometers mounted internally might have helped to separate these modes. That is also why there are seven test modes extracted when there were only six FEM target modes.

\begin{tabular}{|c|c|c|c|}
\hline SHAPE & FREQUENCY & DAMPING & Shape Description \\
\hline REC & (HERTZ) & (\%) & \\
\hline 1 & 28.657 & 0.45 & Squeeze Mode aligned with R and $\theta$ Axis \\
\hline 2 & 30.246 & 0.94 & Squeeze Mode aligned with 60 degrees \\
\hline 3 & 44.857 & 0.54 & Potato Chip Mode aligned with R and $\theta$ Axis \\
\hline 4 & 48.924 & 0.81 & Potato Chip Mode aligned with 60 Degrees \\
\hline 5 & 50.311 & 0.81 & Mass Simulators mode \\
\hline 6 & 54.647 & 0.73 & Tri-Lobe Ovaling Mode \\
\hline 7 & 63.805 & 0.70 & Mass Simulators mode \\
\hline
\end{tabular}

Table 3 CMA Test Modes

The target correlation goals as defined by NASA were: cross-orthogonality $>90 \%$ on the diag onal, $<10 \%$ on the off diag onals, and a frequency difference between test and analytical $<5 \%$. An initial $\mathrm{x}$-ortho was calculated to check the adequacy of the FEM. Table 4 shows frequencies errors as well as high cross-talk in several modes thatexceeded the best practices guidelines mentioned above.

\begin{tabular}{|c|c|c|c|c|c|c|c|c|c|}
\hline & \multicolumn{7}{|c|}{ Test Modes } & \multirow[b]{2}{*}{ Frequency \%Diff } \\
\hline & & 28.57 & 30.27 & 44.84 & 48.86 & 50.33 & 54.65 & 63.61 & \\
\hline \multirow{6}{*}{$\begin{array}{l}\frac{0}{0} \\
\frac{0}{0} \\
\frac{0}{20} \\
\frac{0}{0} \\
\frac{5}{4}\end{array}$} & 22.32 & 92.81 & 35.23 & 5. & 10 & 1.8 & 11.31 & 10.28 & $-21.88 \%$ \\
\hline & 24.93 & 29.77 & 92.36 & 6.6 & 86 & 7.9 & 3.05 & 28 & $-17.65 \%$ \\
\hline & 31.86 & 51 & 24 & 79.94 & 50.70 & 39.60 & 17.53 & 15.01 & $-28.95 \%$ \\
\hline & 35.18 & ate & 3 & 40.32 & 76.95 & 79.43 & 128 & 22.48 & $-27.99 \%$ \\
\hline & 40.61 & 1.0 & 74 & 3. 6 & $5(x)$ & 16.91 & 77.84 & 24.61 & $-25.69 \%$ \\
\hline & 46.85 & 81 & ar & 15.11 & 16.25 & 18.29 & 24.84 & 71.85 & $-26.35 \%$ \\
\hline
\end{tabular}

Table 4 Initial CMA Correlation Results

The next step was to update the FEM and rerun the x-ortho until the correlation goals were achieved. An overall summary of the types of updates that were made to the CMA FEM is presented in Table 5. The final x-ortho table presented in Table 6 does show some $>10 \%$ off diagonal values and frequency differences $>5 \%$. 


\begin{tabular}{|c|l|}
\hline \multicolumn{1}{|c|}{ Type of issue } & \multicolumn{1}{c|}{ Model Update } \\
\hline \multirow{5}{*}{ Modeling } & $\begin{array}{l}\text { FEM did not match as built hardware. } \\
\text { Original FEM lumped masses did not include inertia } \\
\text { properties, decided to model the mass simulators in greater } \\
\text { detail. } \\
\text { Updated the material coordinate orientation on the FWD } \\
\text { and AFT composite panels to be rectangular instead of } \\
\text { radial - this update did not have a large effect on the model } \\
\text { behavior }\end{array}$ \\
\hline Footprinting (heel-toe) & $\begin{array}{l}\text { Increased the rotational stiffness of all the panel to frame } \\
\text { springs. } \\
\text { Merged nodes on the CMA frame to provide stiffer } \\
\text { attachment between rings and frames and prevent heel-toe } \\
\text { motion at the joints. } \\
\text { Added additional row of CBUSH element between aft } \\
\text { panels and lower inboard ring to stop heel-toe motion at the } \\
\text { joints } \\
\text { Added additional row of CBUSH element between aft } \\
\text { panels and longeron/intermediate frames to stop heel-toe } \\
\text { motion at the joints } \\
\text { Added additional row of CBUSH element between inboard } \\
\text { panels and frames and inboard panels and lower inboard } \\
\text { ring to stop heel-toe motion at the joints. }\end{array}$ \\
\hline
\end{tabular}

Table 5 CMA Mass Simulator FEM Model Updating Summary

\begin{tabular}{|c|c|c|c|c|c|c|c|c|c|}
\hline & \multicolumn{7}{|c|}{ Test Modes } & \multirow[b]{2}{*}{ Frequency \%Diff } \\
\hline & & 28.66 & 30.25 & 44.86 & 48.92 & 50.31 & 54.65 & 63.80 & \\
\hline \multirow{6}{*}{ 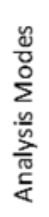 } & 29.74 & 98.90 & & 8.68 & & 0.90 & 805 & 12.53 & $3.77 \%$ \\
\hline & 32.25 & $9=0$ & 94.97 & 250 & 830 & 78 & 29 & 690 & $6.62 \%$ \\
\hline & 42.23 & 810 & 28 & 95.84 & 20.72 & 9.5 & 000 & 700 & $-5.86 \%$ \\
\hline & 47.21 & 9. & 79 & 12.32 & 94.42 & 94.70 & 7.01 & 10.07 & $-3.49 \%$ \\
\hline & 56.84 & 230 & & & & 14.18 & 90.42 & 11.19 & $4.01 \%$ \\
\hline & 61.81 & 1.19 & & 12.04 & & 11.43 & 19 & 90.82 & $-3.13 \%$ \\
\hline
\end{tabular}

Table 6 CMA Mass Simulator FEM FinalCorrelation Results

At the time of performing the correlation, both mode shapes 3 and 4 (see Fig 7) have large internal avionics mass simulators deforming in a similar manner. These internal avionics mass simulators make up over $30 \%$ of the total mas s of the CMA mass simulator so the high off-diagonal values in the x-ortho comparis ons between test and FEM were accepted. Test modes 4 and 5 were not able to be distinguished from each other even after further attempts of adding more accelerometers was utilized. Due to time constraints, these is sues in meeting the correlation goals were accepted on the basis that the correlated modes encompassed the global behavior of the primary load path of the CMA. It turned out that later on in the E-STA correlation, the fact that the CMA mas s simulator FEM was not matching the test databetter in this free-free testing effort should have been a big "red flag" that something in the FEM was still incorrect. This is elaborated upon in later sections of the paper. 


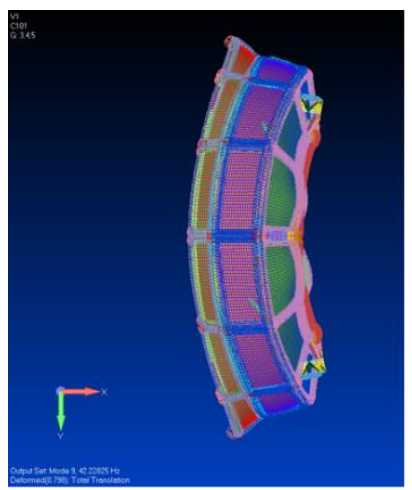

Analysis Mode 3: $42.23 \mathrm{~Hz}$ Potato Chip Mode aligned with $\mathrm{R}$ and $\theta$ Axis

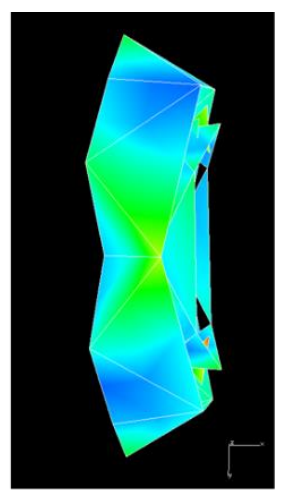

Test Mode 3: $44.857 \mathrm{~Hz}$ Potato Chip Mode aligned with $\mathrm{R}$ and $\theta$ Axis

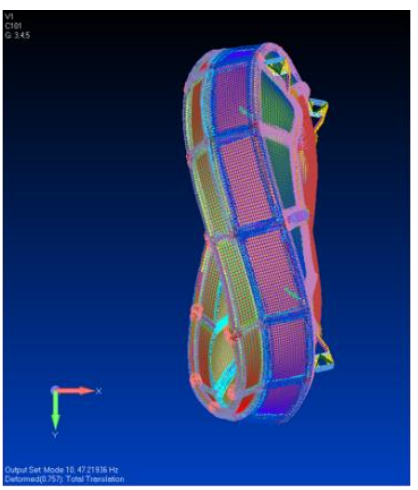

Analysis Mode 4: $47.22 \mathrm{~Hz}$ Potato Chip Mode aligned with 60 Degrees

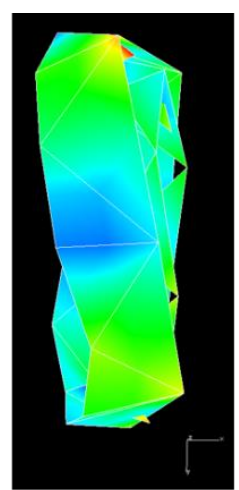

Mode 4: $48.924 \mathrm{~Hz}$ Potato Chip Mode aligned with 60 Degrees

Fig 7 CMA Mas s Simulator Mode Shapes

\section{CREW MODULE/LAUNCH ABORT SYSTEM (CM/LAS) MASS SIMULATOR MODAL TEST}

The CM/LAS mas s simulator modal testing followed theCMA mas s simulator modal test. The CM/LAS mass simulator modal test configuration included all hard ware above its attachment to the CMA mas s simulator. The CM/LAS mass simulator was fastened to the MVF modal floor creating a fixed-base boundary condition. Target modes were selected based on the best practice that greater than $90 \%$ of the modal effective mas s should be captured in all 6 DOF in order to ens ure all the significant modes are considered. Based on this guideline, six high effective mass modes were selected as the primary target modes (hilighted in green in Table 7) and 12 secondary target modes were selected to as sist the overall model correlation effort (hilighted in yellow in Table 7).

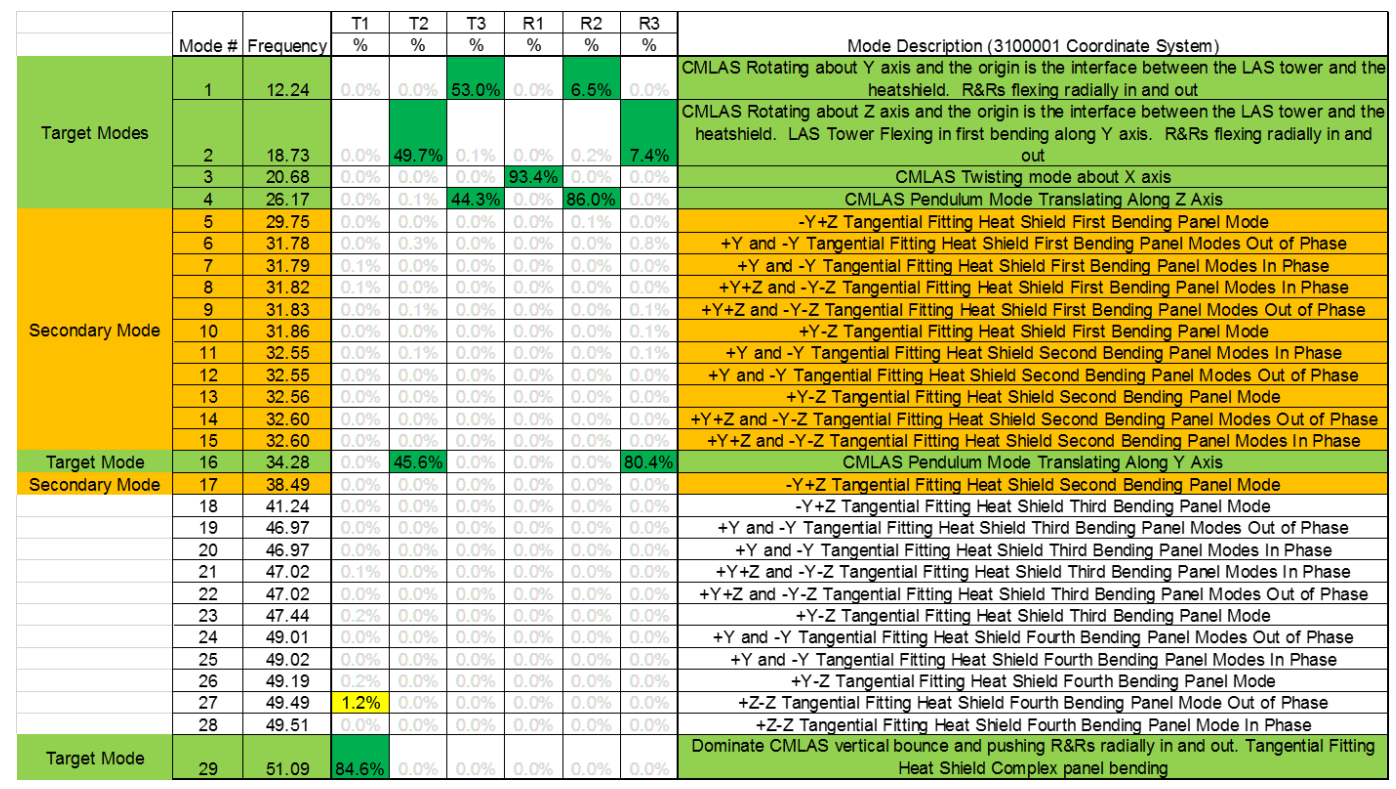

Table 7 CM/LAS ModalEffective Mass Table

A modal pretest analysis was performed on the CM/LAS mass simulator and a final ASET of 66 DOF was selected to independently capture the sixprimary target mode shapes, evidenced by Table 8 . The secondary target modes were not within the pretest guidelines, as observed in Table 9, but it was considered acceptable. The primary target modes are outlined in green in Table 9 for clarification. 


\begin{tabular}{|c|c|c|c|c|c|c|c|c|}
\hline & & & \multicolumn{6}{|c|}{$\begin{array}{l}\text { FEMTAM Cross Drthogonality Table } \\
\text { FEM Shapes }\end{array}$} \\
\hline & & & 1 & 2 & 3 & 4 & 5 & 6 \\
\hline & & Oag & 12.2 & 18.7 & 20.7 & 26.2 & 34.3 & 51.1 \\
\hline \multirow{6}{*}{ 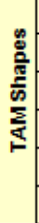 } & 1 & 12.3 & -1.00 & & & & & \\
\hline & 2 & 18.8 & & 1.00 & & & & \\
\hline & 3 & 20.8 & & & 1.00 & & & \\
\hline & 4 & 26.4 & & & & -1.00 & & \\
\hline & 5 & 34.8 & & & & & 1.00 & \\
\hline & 6 & 52.1 & & & & & & 1.00 \\
\hline
\end{tabular}

Table 8 CM/LAS Mass Simulator TAM vs FEM Primary Target Modes Cross-Orthogonality Table

\begin{tabular}{|r|r|r|r|r|r|} 
FEM Mode & Freq $(\mathrm{Hz})$ & TAM Mode & Freq $(\mathrm{Hz})$ & \%Difference & XORTHO \\
\hline 1 & 12.24 & 1 & 12.256 & 0.1 & 100.00 \\
2 & 18.73 & 2 & 18.772 & 0.2 & 100.00 \\
3 & 20.68 & 3 & 20.839 & 0.7 & 100.00 \\
4 & 26.17 & 4 & 26.435 & 1.0 & 99.99 \\
\hline 5 & 29.75 & 5 & 32.441 & 9.0 & 99.97 \\
6 & 31.78 & 6 & 33.864 & 6.6 & 97.35 \\
7 & 31.79 & 7 & 33.898 & 6.6 & 98.92 \\
8 & 31.82 & 9 & 33.929 & 6.6 & 89.70 \\
9 & 31.83 & 8 & 33.928 & 6.6 & 85.38 \\
10 & 31.86 & 10 & 33.945 & 6.5 & 94.99 \\
11 & 32.55 & 11 & 34.823 & 7.0 & 76.94 \\
12 & 32.55 & 12 & 34.842 & 7.0 & 95.51 \\
13 & 32.56 & 13 & 34.851 & 7.0 & 89.01 \\
14 & 32.60 & 14 & 34.870 & 7.0 & 97.75 \\
15 & 32.60 & 15 & 34.870 & 6.9 & 96.53 \\
\hline 16 & 34.28 & 16 & 34.893 & 1.8 & 82.57 \\
\hline 17 & 38.49 & 17 & 44.513 & 15.7 & 99.56 \\
\hline 18 & 51.09 & 18 & 52.121 & 2.0 & 99.82 \\
\hline
\end{tabular}

Table 9 CM/LAS Pretest Results - Primary (Outlined in Green) and Secondary Target Modes

Nine impact locations were determined prior to testing using ATA En gineering's IMAT ${ }^{\circledR}$ software package, one of which can be seen in the left half of Fig 8. Additionally, eleven shaker runs [single input multiple output (SIMO) and multiple input multiple output (MIMO)] were als o performed. The shaker placement is better illustrated in the right images in Fig 8.
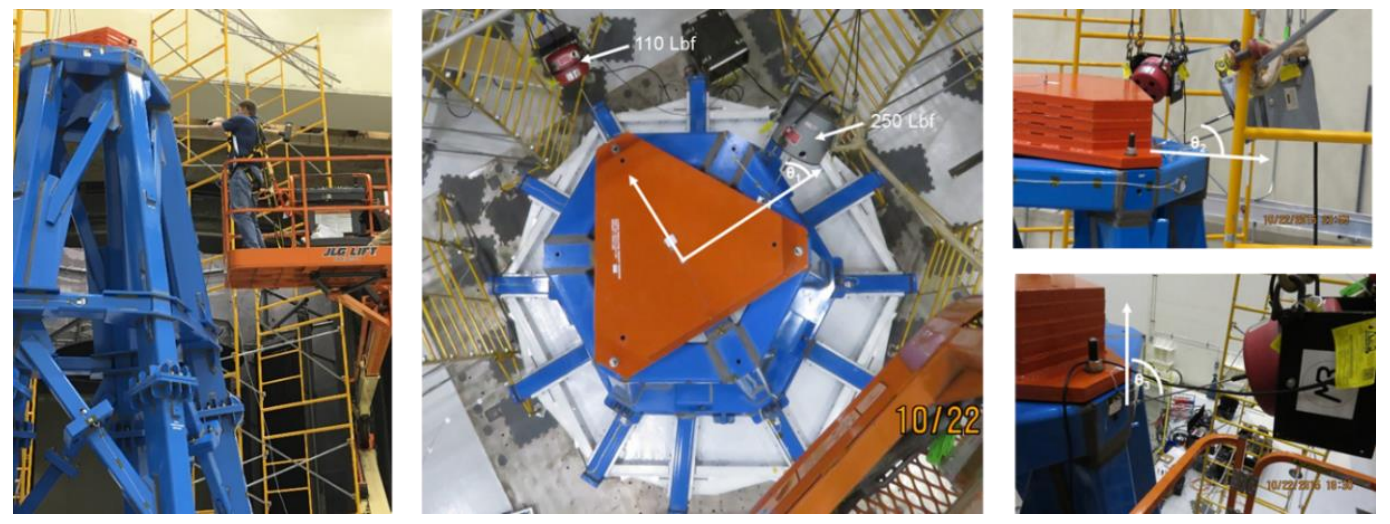

Fig 8 CMLAS Simulator Test Setups: Impact Hammer (left) - Shaker Setup (mid and right)

Modal parameters were extracted for all runs and it was found that the modal parameters were very similar from test to test. Based on the modal parameter data, it was decided to use the single portable shaker method as the final technique for modal extraction because offered the cleanest data. Table 10 lists the six primary target modes in addition to one other higher frequency mode. 


\begin{tabular}{|c|c|c|l|}
\hline $\begin{array}{c}\text { SHAPE } \\
\text { REC }\end{array}$ & $\begin{array}{c}\text { FREQUENCY } \\
\text { (HERTZ) }\end{array}$ & $\begin{array}{c}\text { DAMPING } \\
(\%)\end{array}$ & \multicolumn{1}{c|}{$\begin{array}{c}\text { SHAPE } \\
\text { DESCRIPTION }\end{array}$} \\
\hline 1 & 13.31 & 0.3 & $\begin{array}{l}\text { CMLAS Rotating about Y axis and the origin is the } \\
\text { interface between the LAS tower and the heatshield. }\end{array}$ \\
\hline 2 & 20.87 & 0.37 & CMLAS Twisting mode about X axis \\
\hline 3 & 21.18 & 0.34 & $\begin{array}{l}\text { CMLAS Rotating about Z axis and the origin is the } \\
\text { interface between the LAS tower and the heatshield. } \\
\text { Heat Shield is rotating about X Axis }\end{array}$ \\
\hline 4 & 25.74 & 0.61 & CMLAS Pendulum Mode Translating Along Z Axis \\
\hline 5 & 32.42 & 0.71 & CMLAS Pendulum Mode Translating Along Y Axis \\
\hline 6 & 49.05 & 0.94 & CMLAS vertical bounce mode \\
\hline 7 & 57.2 & 0.25 & CMLAS Out of phase torsion with Heat shield \\
\hline
\end{tabular}

Table 10 CMLAS Simulator Modal TestResults

The same cross-orthogonality and frequencies goals used in the CMA modal tes ting were applied to the CMLAS correlation effort. To understand the effect of the modelchanges during the correlation process, the teamstarted the correlation with the as-delivered FEM as shown Table 11. It can been seen that the as-deliveredFEM did not provide a good starting point. The first target mode was the only mode that met the main diagonal goal; additionally, using the FEM as it was delivered to NASA GRC, the pretest would have not been accurate enough to provide proper ins trumentation placement.

\begin{tabular}{|c|c|c|c|c|c|c|c|c|c|}
\hline \multicolumn{10}{|c|}{ As Delivered XORTHO (07/27/2015) } \\
\hline & \multicolumn{8}{|c|}{ Test Extracted Mode Shapes } & \multirow{2}{*}{$\begin{array}{l}\text { Diff. } \\
(\%)\end{array}$} \\
\hline \multirow{8}{*}{ 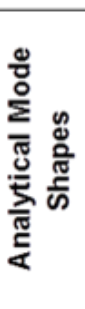 } & Freq. $(\mathrm{Hz})$ & 13.29 & 20.87 & 21.16 & 25.70 & 32.32 & 49.24 & 57.19 & \\
\hline & 11.85 & 98.65 & 7.36 & 11.43 & 26.04 & 1.03 & 5.40 & 1.84 & $11 \%$ \\
\hline & 13.99 & 5.06 & 51.67 & 27.71 & 33.85 & 11.67 & 16.69 & 33.63 & $33 \%$ \\
\hline & 16.89 & 0.68 & 37.34 & 38.32 & 49.19 & 27.45 & 26.48 & 23.07 & $34 \%$ \\
\hline & 18.37 & 7.40 & 57.98 & 84.56 & 32.48 & 30.94 & 0.28 & 3.39 & $13 \%$ \\
\hline & 21.48 & 4.57 & 0.75 & 9.24 & 0.07 & 56.23 & 13.45 & 7.87 & $34 \%$ \\
\hline & 48.32 & 2.83 & 4.14 & 0.65 & 6.50 & 2.07 & 78.06 & 6.67 & $2 \%$ \\
\hline & 58.04 & 1.30 & 29.91 & 11.17 & 23.58 & 5.02 & 30.66 & 89.15 & $-1 \%$ \\
\hline
\end{tabular}

Table 11 CM/LAS Mass Simulator As-delivered Cross-Orthogonality

Table 12 shows the correlation results using a FEM that was updated prior to the start of testing to better reflect the as-built hardware configuration. As previously mentioned, significant mismatches between the as-delivered FEM and the actual test hardware were noted prior to commencing testing activities. This data reaffirms what it is already known, but many times not applied: the FEM needs to accurately represent the as-built hardware. This not only provides more accurate pretest analysis and saves time during the model correlation effort, but is critical to ensuring the "test correlated" FEM accurately represents critical load paths.

\begin{tabular}{|c|c|c|c|c|c|c|c|c|c|}
\hline \multicolumn{10}{|c|}{ X-Ortho: $10 / 20 / 2015$} \\
\hline \multirow{9}{*}{ 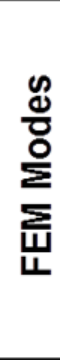 } & \multicolumn{8}{|c|}{ Test Modes } & \multirow[b]{2}{*}{$\%$ Diff } \\
\hline & Freq. & 13.29 & 20.88 & 21.16 & 25.72 & 32.33 & 48.98 & 57.21 & \\
\hline & 12.26 & 98.40 & 0.75 & 13.64 & 22.19 & 2.26 & 1.21 & 2.86 & $8 \%$ \\
\hline & 18.73 & 8.15 & 20.25 & 91.11 & 23.36 & 32.32 & 4.47 & 5.48 & $10 \%$ \\
\hline & 20.33 & 1.80 & 97.40 & 35.05 & 11.01 & 0.30 & 2.28 & 13.55 & $4 \%$ \\
\hline & 25.89 & 12.14 & 4.11 & 9.45 & 93.75 & 10.31 & 2.76 & 0.09 & $-1 \%$ \\
\hline & 33.95 & 6.74 & 6.11 & 11.82 & 5.42 & 94.01 & 1.09 & 2.09 & $-5 \%$ \\
\hline & 50.94 & 2.26 & 0.16 & 0.89 & 5.15 & 0.20 & 99.51 & 6.15 & $-4 \%$ \\
\hline & 58.48 & 0.02 & 5.29 & 1.60 & 0.62 & 0.94 & 0.09 & 98.89 & $-2 \%$ \\
\hline
\end{tabular}

Table 12 CM/LAS Mass Simulator Cross-Orthogonality Results using Updated FEM 
The modelupdating of the FEM posttest still required an updating effort even with theinclusion of pretest FEM updates. The updates made after the test was completed is summarized in Table 13.

\begin{tabular}{|c|c|}
\hline Issue & Fix \\
\hline $\begin{array}{l}\text { The test team first identified that the CMLAS tower had a very } \\
\text { significant amount of non-structural mass all over it. The CG of the } \\
\text { tower section was not accurate per the CMLAS mass and CG report }\end{array}$ & $\begin{array}{l}\text { Update 1a-All overlapping beam elements were } \\
\text { shortened and connected using RBE2 elements. } \\
\text { Update } 1 \mathrm{~b} \text { - Gusset Plates were extended through beam } \\
\text { elements. } \\
\text { Update 1c - Horizontal beams modified to include extra } \\
\text { plate thickness on top and bottom surfaces } \\
\text { Update } 1 \mathrm{~d} \text { - Connection plates were included as extra } \\
\text { thickness in the beam element properties at all welded } \\
\text { joints on the LAS tower. } \\
\text { Update } 1 \mathrm{e} \text { - Connection plates where the upper and } \\
\text { lower LAS towers connect to each other were added into } \\
\text { the model using shell elements } \\
\text { Update 1f - Removed the previously added corner } \\
\text { gussets. }\end{array}$ \\
\hline $\begin{array}{l}\text { The CMLAS FEM was still too heavy according to the mass and CG } \\
\text { report supplied by LM }\end{array}$ & $\begin{array}{l}\text { Engineers started to take measurements of the test } \\
\text { hardware and compare to FEM. Several geometric } \\
\text { issues with the model were uncovered. } \\
\text { Update } 2 \text { a - Top of the tower was modeled 14" wider } \\
\text { than as-built hardware } \\
\text { Update } 2 \text { b - Entire CMLAS structure was positioned 2" } \\
\text { higher above the D-Brackets than as-built hardware } \\
\text { Update 2c - Support structure between the CMLAS base } \\
\text { and the heat shield was modeled into the FEM, but was } \\
\text { not present in the as-built hardware } \\
\text { Update } 2 \mathrm{~d} \text { - Mass Simulator at the top of the CMLAS } \\
\text { tower was modeled with four connections when in the as- } \\
\text { built hardware it only had three. Also added in mass } \\
\text { moments of inertia. } \\
\text { Update } 2 \mathrm{e} \text { - Mass properties of the super nut at each D- } \\
\text { Bracket location was added into the FEM. }\end{array}$ \\
\hline D-Bracket Stiffness & $\begin{array}{l}\text { The base springs created before the test were greatly } \\
\text { simplified to just having four on the corners and three } \\
\text { along the middle support brace. } \\
\text { Noticed that the boundary conditions at the base of the D- } \\
\text { Brackets was not what was originally planned. }\end{array}$ \\
\hline
\end{tabular}

Table 13 CM/LAS Mass Simulator Model Update Summary

When including the model updates to the FEM, both pre and posttest, as well as modifying the boundary conditions at the base of the CMLAS, the correlation started to look much improved as seen in Table 14.

\begin{tabular}{|c|c|c|c|c|c|c|c|c|c|}
\hline & \multicolumn{8}{|c|}{ Test Extracted Mode Shapes } & \multirow{2}{*}{$\begin{array}{l}\text { Freq } \\
\text { Diff. }\end{array}$} \\
\hline \multirow{8}{*}{ 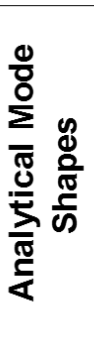 } & & 13.32 & 20.91 & 21.19 & 25.78 & 32.44 & 49.10 & 57.21 & \\
\hline & 13.55 & 98.71 & 2.11 & 11.45 & 7.24 & 6.07 & 1.30 & 0.08 & $-2 \%$ \\
\hline & 21.17 & 4.25 & 85.22 & 58.39 & 9.75 & 0.60 & 2.91 & 19.72 & $-1 \%$ \\
\hline & 21.20 & 10.18 & 50.97 & 79.93 & 8.76 & 4.84 & 1.83 & 4.35 & $0 \%$ \\
\hline & 25.42 & 1.75 & 0.68 & 8.41 & 98.24 & 12.16 & 2.78 & 0.98 & $1 \%$ \\
\hline & 31.81 & 6.32 & 3.86 & 1.22 & 10.39 & 98.66 & 1.62 & 0.67 & $2 \%$ \\
\hline & 50.52 & 1.85 & 0.25 & 1.04 & 0.75 & 3.12 & 98.99 & 3.25 & $-3 \%$ \\
\hline & 61.71 & 0.21 & 8.67 & 2.54 & 2.59 & 2.07 & 8.02 & 98.00 & $-8 \%$ \\
\hline
\end{tabular}

Table 14 CM/LAS Mass Simulator Cros s-Orthogonality after First Round of Model Updates 
At this point, all the frequencies of the primary target modes were within acceptable ranges. However, Mode \#3 still did not match the test shape as can be seen with the high off diagonal values in Table 14. There was rotation of the heat shield that was not being mimicked by the analytical model. Engineers first attributed this to the asymmetrical beam gussets that increased one side of the beammore than the other. In order to better capture this asymmetrical stiffness, the upper part of theFEM was recreated using 2D shell elements over the previously used 2D beam elements. This gave the engineers better ability to accurately model the gusset plates and joints. Fig 9 shows how en gineers took advantage of the hardware symmetry and created only a mesh of $1 / 6$ of the section and then duplicating it 5 additionaltimes.

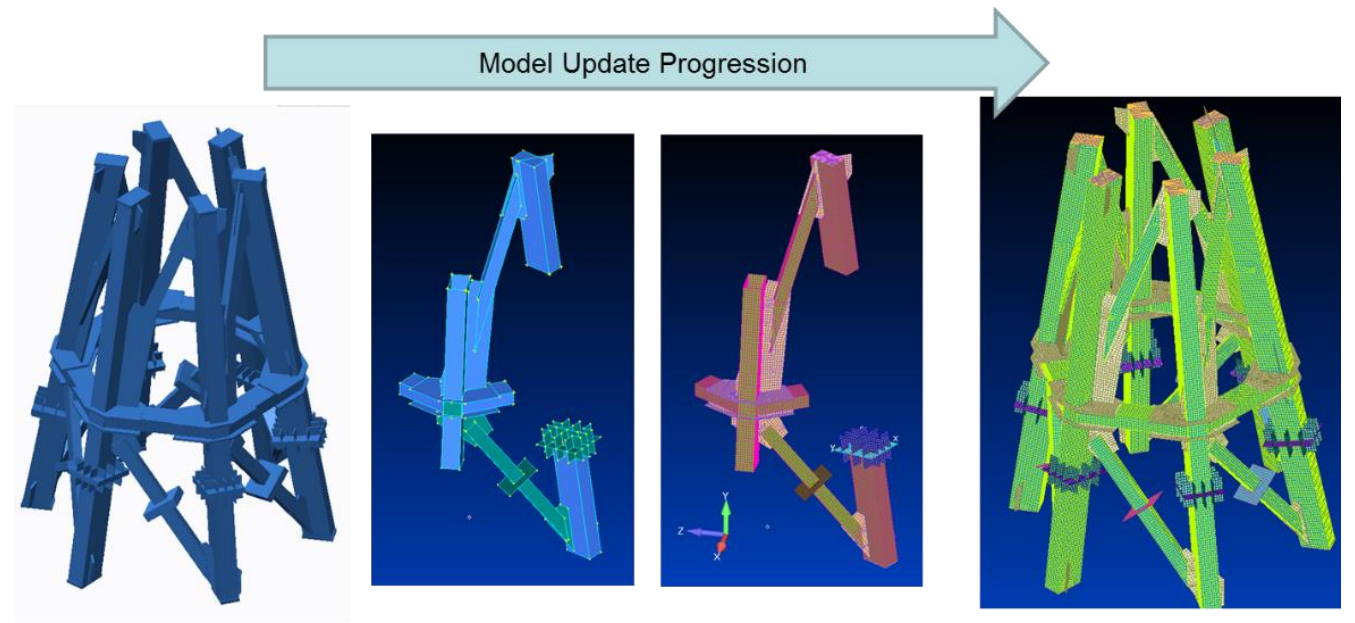

Fig 9 LAS Tower Shell Model

As shown in Table 15, the change to shell elements on the LAS tower did not address the primary is sue of lowering the off diagonal values of Mode\#3. However, it did correct the frequencies of secondary modes found in the test data in the $60 \mathrm{~Hz}$ range. These secondary modes had been incorrectly predicted in the FEM in the $50 \mathrm{~Hz}$ range.

\begin{tabular}{|c|c|c|c|c|c|c|c|c|c|}
\hline \multicolumn{10}{|c|}{ XORTHO (After Model Updates 4) } \\
\hline \multirow{9}{*}{ 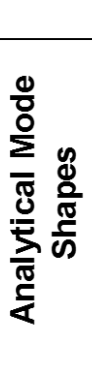 } & \multicolumn{8}{|c|}{ Test Extracted Mode Shapes } & \multirow{2}{*}{$\begin{array}{l}\text { Freq. } \\
\text { Diff. }\end{array}$} \\
\hline & & 13.31 & 20.87 & 21.18 & 25.74 & 32.42 & 49.11 & 57.19 & \\
\hline & 13.41 & 98.88 & 1.16 & 10.84 & 4.04 & 4.87 & 1.11 & 0.49 & $-1 \%$ \\
\hline & 20.96 & 3.03 & 94.48 & 46.35 & 9.87 & 0.26 & 2.14 & 12.22 & $0 \%$ \\
\hline & 21.00 & 10.19 & 30.37 & 87.20 & 11.92 & 2.10 & 1.73 & 1.13 & $1 \%$ \\
\hline & 25.19 & 1.08 & 1.78 & 10.20 & 97.80 & 11.33 & 2.58 & 0.46 & $2 \%$ \\
\hline & 31.52 & 5.72 & 4.01 & 2.87 & 11.24 & 98.82 & 1.55 & 0.58 & $3 \%$ \\
\hline & 50.01 & 1.46 & 1.97 & 1.54 & 1.84 & 2.60 & 98.30 & 1.64 & $-2 \%$ \\
\hline & 59.46 & 0.03 & 2.70 & 0.36 & 1.91 & 2.03 & 3.28 & 95.86 & $-4 \%$ \\
\hline
\end{tabular}

Table 15 Cross-Orthogonality after LAS Tower Model Updates

Finally, it was determined that the only way to affect only Mode \#3 without changing the others was to introduce a mass offset at the top of the tower along the $\mathrm{Z}$ axis. Becaus e this $6500 \mathrm{lb}$ mass simulator (orange part in Fig 10) was over 18 feet above the base, engineers believed changing that mass offset just a small amount could have a large impact on the modes. The CG of the orange mass was moved along the axis of the black arrow in Fig 10. To determine sensitivity to it, multiple iterations were done using offsets of 2 inches, 1 inch, 0.5 inches, and 1.125 inches. The offset of 1.125 inches was decided to bethe final value. 


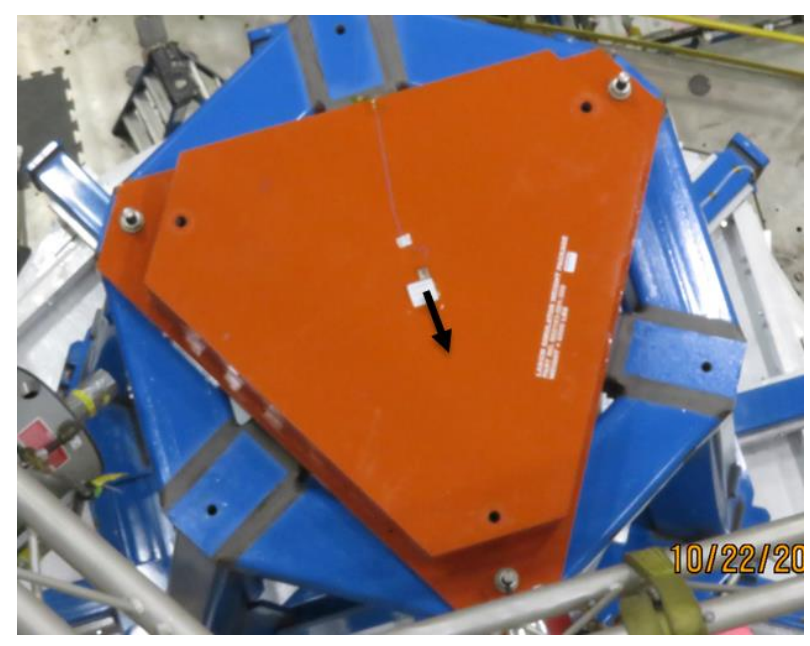

Fig 106500 lbs Mass Simulator

The final x-ortho results are shown in Table 16. At this point, it was determined that all target modes were successfully extracted. Additionally, the secondary target modes which had mostly local dynamics of the secondary support beams were able to be fully correlated in the FEM per the NASA guidelines.

\begin{tabular}{|c|c|c|c|c|c|c|c|c|c|}
\hline \multicolumn{10}{|c|}{ Final Correlated XORTHO (11/10/2015) } \\
\hline & \multicolumn{8}{|c|}{ Test Extracted Mode Shapes } & \multirow{2}{*}{$\begin{array}{c}\text { Freq. Diff. } \\
\text { (\%) }\end{array}$} \\
\hline \multirow{8}{*}{ 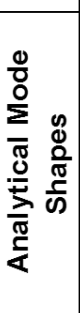 } & Freq. (Hz) & 13.31 & 20.87 & 21.18 & 25.74 & 32.42 & 49.11 & 57.19 & \\
\hline & 13.55 & 98.79 & 1.23 & 11.01 & 4.35 & 4.80 & 1.24 & 0.51 & $-2 \%$ \\
\hline & 20.93 & 1.17 & 98.82 & 7.98 & 4.19 & 1.88 & 2.76 & 12.35 & $0 \%$ \\
\hline & 21.19 & 10.78 & 8.44 & 98.39 & 14.77 & 2.70 & 0.70 & 1.63 & $0 \%$ \\
\hline & 25.38 & 1.40 & 1.79 & 10.06 & 97.79 & 11.24 & 2.33 & 0.25 & $1 \%$ \\
\hline & 31.88 & 5.80 & 4.31 & 2.05 & 11.04 & 98.80 & 1.60 & 0.36 & $2 \%$ \\
\hline & 50.31 & 1.22 & 2.00 & 1.43 & 1.80 & 2.50 & 98.28 & 1.88 & $-2 \%$ \\
\hline & 59.39 & 0.05 & 2.35 & 0.44 & 1.82 & 1.80 & 2.85 & 95.87 & $-4 \%$ \\
\hline
\end{tabular}

Table 16 CMLAS FinalCross-Orthogonality Results

\section{E-STA STACK FEM CORRELATION}

After all building block modal testing was completed, the subassemblies were assembled together. The full stack underwent both acoustic testing, low level randomvibration testing, and finally full level sine vibration testing. After the conclusion of E-STA sine vibration testing, correlation work on the fully integrated stack FEM began. The correlation approach follows these five steps:

1. CAD-FEM Comparison

2. Measure Test Article Mass

3. Consider Nonlinearities

4. Hardware Interface Modeling Practices

5. Confirming the Load Path

\section{CAD-FEM COMPARISON}

Comparing as-built CAD to FEM is one of the most important steps in correlation. Ideally, this is done before testing even begins. Even when a FEM is received froma different group, the correlation group should still performan independent CADFEM comparis on. There are several steps to the comparison: check geometry placement mis match, thickness comparisons, composite layup comparisons, and mas s property comparis ons. Test eng ineers should have full access to the as -built CAD or at the very least the drawings to enable these comparisons to be made. 
The CMA model was thought to have been acceptably correlated by standard metrics during building block testing, thus a CAD-FEM review was not performed. It was discovered during the stack CAD-FEM review many months later that the CMA FEM was a design froman older mis sion. This is evident in Fig 11 displaying a major load bearing section of the CMA. The light green is the CAD, the rest is from the FEM. The aft panel is placed at a different angle, and many of the cross-brace supports are in different positions and angles. Property thicknesses of different frame members were up to $100 \%$ different from the CAD. The CMA was fully remodeled from scratch by the correlation team. Looking back, the correlation of the CMA during the free-freetesting showed signs of modeling is sues but were ignored due to schedule pressures. Had these CAD-FEM comparis ons been done prior to the CMA free-free modal test even occurring, a significant amount of time could have been saved throughout the rest of the testing campaigns.

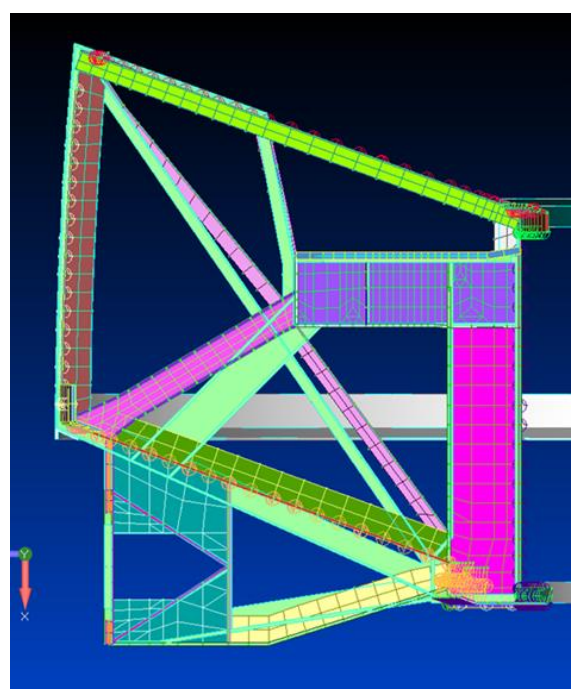

Fig 11 CAD-FEM Comparis on of CMA Cross-Section

\section{MEASURE TEST ARTICLE MASS}

Ideally, the subassemblies in a building block approach should be individually weighed, and the FEM should be updated to reflect the measured mass. In theE-STA FEM, several components' mas ses were updated to reflect as-measured mass. It was during the mass comparis on effort that it was discovered that the FEM was mis sing $31 \%$ of the propellant mas s fromtwo of the tanks (approximately $3000 \mathrm{lbs}$ ). This may nothave been otherwise discovered without the presence of as-measured masses. The smaller the subassemblies that the full stack can have the as-measured masses documented in the better. It allows the engineer performing the correlation to "zero" in on any is sues that may be present. It is also very important to keep nonstructural mass modeling to a minimum in the FEM. Some of the building block subassemblies relied on modeling significant structural members with non-structural mass or with concentrated masses without any inertia properties. These methods should be avoided if one hopes to have an accurate FEM.

\section{CONSIDER NONLINEARITIES}

Es pecially for large, complexspacecraft, it is possible that the test article will exhibit nonlinear behavior. In E-STA, there was a large amount of nonlinearity in the stack especially located to the joints. The modal frequencies extracted from the low level randomvibration tests were up to $40 \%$ higher than the modes extracted fromthe full flight level sine tests. At high levels, the joints began to behave differently than at low level. This should be taken into consideration when attempting to correlate a FEM. Usually, an engineer will first attempt to correlate the FEM to the low level test data where the joints are still behaving linearly. It is important that they understand from the test data though which joints are exhibiting significant non-linear behavior, and take steps in the low level correlation effort to implement modeling features that will be easily modified to capture the non-linear behavior at high excitation levels. This is generally done with CBUSH springs that can have their stiffness changed significantly without any remodeling effort. While it's a key part of the correlation process to match the lower level data, that really isn't the final goal. The finalgoal has to be matching the higher level excitation datadue to it most closely resembling the flight loading conditions of the hard ware. This entire process can be extremely time consuming . 


\section{HARDWARE INTEFACE MODELING PRACTICES}

It is important to scan the entire FEM to check for good modeling practices, but because the building block approach was used in E-STA, the primary focus was only on the major interfaces. A great place to start is these checks is by reviewing the "footprinting" of the interface connections. "Footprinting" is the use of s pider RBEs to spread the load of one CBUSH interface element to the area over which the physical joint acts. This modeling technique prevents heel-toe motion of bolted flanges in the FEM and properly capture the stiffness of the interface. Traditionally, only a single CBUSH is utilized to transfer load from one large structure to another at bolted interfaces. Even when footprints are utilized, they are often times still too small. Foot prints should be accurately placed and spaced at all interfaces if one hopes to capture the true stiffness of major joints. Sometimes, due to oversimplification of the loads FEM, foot printing cannot be implemented. It is at this point when engineers should take the time to go into the FEM and increase the fidelity.

While footprinting works great for large flange interfaces that are bolted together, it may not be the final answer for more complicated interfaces such as pyrotechnic separation joints, alignment bearings and pins, or other intricate mechanisms may be present. The engineer performing the correlation should be reviewing the se major interfaces and inquiring about the following:

1. How much of the mechanismis supposed to be included in any simplified modeling (generally CBUSH elements)?

2. What are the reasonable ranges of stiffness for CBUSHelements at each interface?

3. Is there component level testing to backup these existing stiffness values?

E-STA has several complicated interfaces that utilize py rote chnic joints because they need to separate at different stages during the launch. These complicated mechanisms should not be modeled with single CBUSH elements or even with small number of simple 2D elements. Oversimplification of the FEM, especially at the major interfaces, was one of the leading reasons why the E-STA stack did not match the test results.

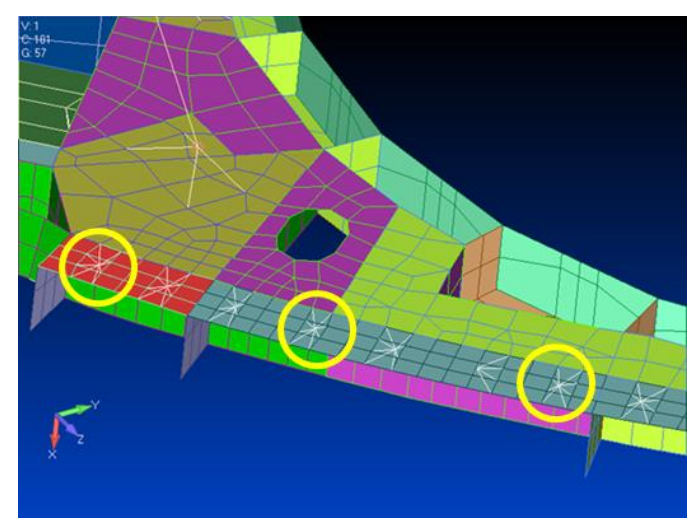

Fig 12 Examples of Footprinting to Capture Interface Flange Stiffness

In addressing the second bullet above, there have been far too many instances where CBUSH elements at joints have been modeled either with too high or too low of stiffness values. Starting with the problemof too low of stiffness, one should take great care in avoiding using zeros as a stiffness value in any one of the sixdegrees of freedom. Even values below $100 \mathrm{lbf} / \mathrm{inch}$ can lead to unrealis tic FEM behavior. If the primary stiffness direction of the interface is modeled with 1,000,000 lbf/inch or higher, then placing a value between $100-1000 \mathrm{lbf} /$ inch in the non-primary directions is highly advised. On the other hand, if a CBUSH requires extremely large stiffness values to correlate an interface, one should look into seeing if more fidelity should be added in. There is a good chance that the CBUSH is trying to represent too much of the hardware and cannot accurately do so.

Finally, in some instances, there has been previous component level testing activities performed to help establish the mechanism stiffnes s values used in the FEM. It is a very wise practice to utilize this information during the correlation, but with a caveat. Do not blindly accept these component test results as the absolute truth. On some occasions, only simplified loading can be introduced at the component level that does not accurately reflect what occurred in the large scale testing. The engineer 
performing the correlation must first understand the loading applied during the fully as sembled testing and then compare that with the load implemented during any simplified component testing.

\section{CONFIRMING THE LOAD PATH}

The extracted modal parameters of natural frequencies and mode shapes are not the only metrics that should be utilized in model correlation, es pecially of large vehicles similar to E-STA. It has been observed that large vehicles such as E-STA rely on several different parallel paths to carry load throughout the vehicle. In E-STA, the one of these major parallel load paths consisted of an outer load path (SAJ Fairings \& PSM) and an inner load path (ESM Longerons). There is a problem that can occur, and did with E-STA, when only the modal parameters of natural frequency and mode shapes are utilized for the correlation. The problemis that one of the two parallel load paths can be significantly incorrect, but the other load path is over compensating for it, albeit incorrectly, and thus theFEM will still predicts a matching natural frequency and mode shape. The cross-orthogonality matrices are not sensitive to showing inaccuracies of the parallel load paths because overall mode shapes and modal mass as sociated with the FEM shapes are still, as a whole, correctly mimicking the test results. Table 11 shows the $\mathrm{x}$-ortho comparis on of the E-STA stack, and indicates a very acceptable mode shape correlation between the test results and FEM predictions. However, looking at Fig 13, it is obvious that this same FEM is predicting far more load going through the inner path (ESM Longerons) than the actual test results revealed. In E-STA, only the inner load path had full bridge strain gages to allow for this load comparis on to take place between the FEM and test results. The teamutilized a MSCNastran SOL 111 frequency base drive simulation to calculate FRFs of these strain gauges at the longerons. Even after the correlation was complete, and the natural frequencies were brought into within the $<5 \%$ frequency difference goal, there was still significant differences in the FEMs prediction of the inner load path results. The outer load path was not instrumented and measured during this testcampaign thus it was not possible to confirm what engineers suspected the issue was. Engineers suspected and confirmed through sensitivity studies that a mechanism on the outer load path was most likely modeled with too low of stiffness and thus the inner load path was overcompensating for it. Recommendations to future tests were made to ensure both load paths would be measured.

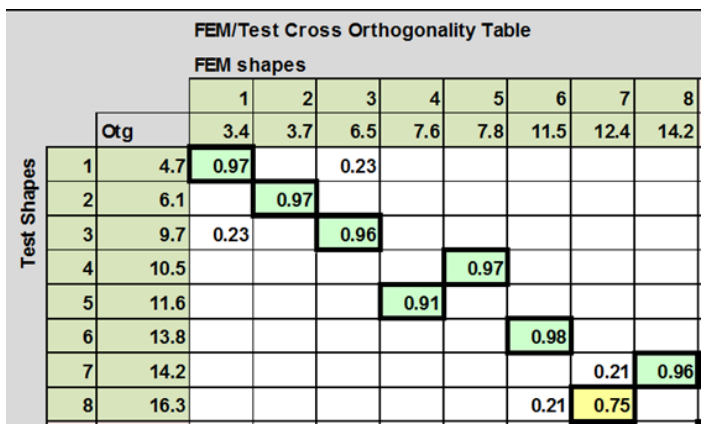

Table 17 OriginalCross-Orthogonality Matrix

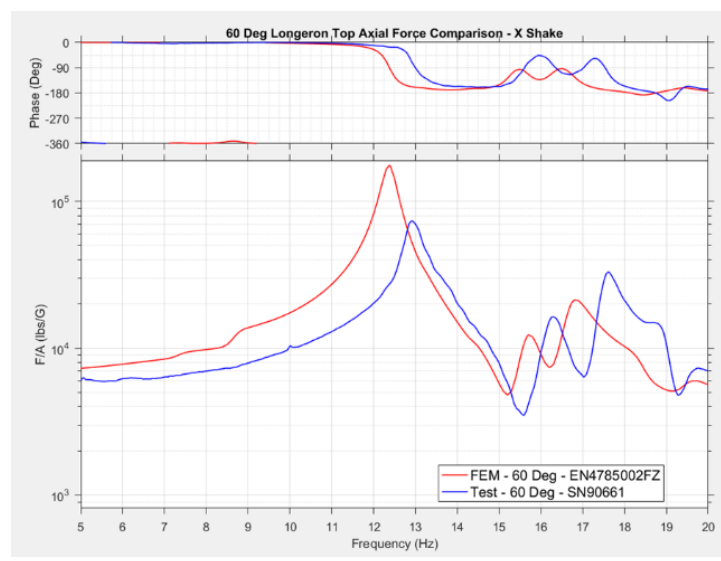

Fig 13 Axial Shake Inner Load Path FRF 
Another point to keep in mind is that the load share can be different during dynamic loading and static loading. The ESM has went through static load testing and was partially correlated to this test data prior to the start of E-STA testing. This static testing was not able to cause joints to slip and move relative to each other in the same way they did during dynamic testing. Thus, even if a model is "correlated" to static testing, care should be taken to understand how the differences between the static and dynamic loading manifes ts itself in the hard ware.

\section{E-STA CORRELATION PROGRESS}

Immediately following the conclusion of the test, theFEM, comprised of individually correlated components based on building block testing, was compared to the modal test data. However, Table 18 illustrates the FEM to be up to $62 \%$ too soft when compared to the test data.

\begin{tabular}{|c|c|c|c|}
\hline Mode & FEM & Test & Diff. \\
\hline 1BZ & 3.37 & 4.73 & $40 \%$ \\
\hline 1BY & 3.74 & 6.05 & $62 \%$ \\
\hline 2BZ & 6.52 & 9.66 & $48 \%$ \\
\hline 2BY & 7.57 & 11.58 & $53 \%$ \\
\hline T & 7.84 & 10.51 & $34 \%$ \\
\hline A & 11.47 & 13.84 & $21 \%$ \\
\hline OZ & 12.43 & 16.32 & $31 \%$ \\
\hline OY & 14.24 & 14.22 & $0 \%$ \\
\hline
\end{tabular}

Table 18 Low Level Random Test Frequency Comparison

After struggling to correlate the model, the teamlooked into the nonlinear behavior of the E-STA during higher level sine testing. It was decided that the FEM was currently closer to being correlated to the high-level sine excitation test data. In an attempt to save time, it was decided to try to use the high-level sine data for the correlation because, as shown in Table 19, the max frequency difference when comparing to the same FEM was $22 \%$. It is important to note that the torsion mode of the stack denoted with an * in Table 19 and in Table 20 was only able to be extracted fromthe low level randomtest results due to there not being significant sine excitation in a torsional direction.

\begin{tabular}{|c|c|c|c|}
\hline Mode & FEM & Test & Diff. \\
\hline 1BZ & 3.37 & 3.77 & $12 \%$ \\
\hline 1BY & 3.74 & 4.32 & $16 \%$ \\
\hline 2BZ & 6.52 & 7.66 & $17 \%$ \\
\hline 2BY & 7.57 & 9.27 & $22 \%$ \\
\hline $\mathrm{T}^{*}$ & 7.84 & 11.06 & $41 \%$ \\
\hline $\mathrm{A}$ & 11.47 & 12.98 & $13 \%$ \\
\hline $\mathrm{OZ}$ & 12.43 & 13.31 & $7 \%$ \\
\hline $\mathrm{OY}$ & 14.24 & 13.46 & $-5 \%$ \\
\hline
\end{tabular}

Table 19 High Level Sine Test Frequency Comparison

After several months of correlating the FEM, the vehicle modes were able to be brought within $6 \%$ of the sine test data, as seen in Table 20 (exception of torsion mode). This was a large improvement over the original FEM, however, the correlation was never fully completed due to the in ability to confirm why load share between the vehicles parallel load paths did not match the test results. 


\begin{tabular}{|c|c|c|c|}
\hline Mode & FEM & Test & Diff. \\
\hline 1BZ & 4.03 & 3.77 & $-6 \%$ \\
\hline 1BY & 4.53 & 4.32 & $-5 \%$ \\
\hline 2BZ & 7.7 & 7.66 & $-1 \%$ \\
\hline 2BY & 9.22 & 9.27 & $1 \%$ \\
\hline $\mathrm{T}^{*}$ & 9.54 & 11.06 & $16 \%$ \\
\hline A & 13.62 & 12.98 & $-5 \%$ \\
\hline OZ & 13.2 & 13.31 & $1 \%$ \\
\hline OY & 14.5 & 13.46 & $-7 \%$ \\
\hline
\end{tabular}

Table 20 Post-Correlation High LevelSine Frequency Comparis on

\section{LESSONS LEARNED FROM CORRELATION CAMPAIGN}

In summary, four out of the five main subassemblies of the E-STA stack were correlated prior to the E-STA vibration tests. Two of those pieces were modally tested and successfully correlated by NASA GRC LMD branch. The building block modal test approach allowed en gineers to do more accurate pretest analysis on the fullESTA stack, as well as make a very difficult correlation effort a much more manageable one. Those same en gineers were then heavily involved with the correlation of the full E-STA stack. That experience gave them the opportunity to dis cover is sues that they had not well understood during the building block tes ting as well as determine other les sons learned from the entire process. Those lessons are:

- Always performCAD-FEM comparis ons, even if there is good correlation to test, and ideally before test begins to save time for actual correlation.

- Carry out the building block modal tes ts with boundary conditions that closely resemble theconfiguration they will be in during the fully assembled testing. If a component is in the middle of the stack, attempt to mas s load both sides of the interface.

- Measure the mass of each subassembly and compare toFEM.

- Check for nonlinear behavior in the test data and develop a basic understanding of how to implement it in the FEM. Always correlate to the lower level first, but ens ure the correlation is ultimately carried out to the higher level excitation which more represents the flight.

- Check model for good modeling practices. Make sure major interfaces are "footprinted" appropriately, mechanisms are modeled with sufficient fidelity, and ensure all CBUSH values are within appropriateranges.

- For vehicles with a dual load path, it is critical to instrument both load paths with strain gages and then verify that your correlated model is correctly simulating the load dis tribution.

After every test effort, there is always lessons learned that engineers hope to pass on so that the same mistakes are not duplicated. It is the hope that through this paper, some of these les sons will be utilized to make future large scale testing efforts even more successful than this.

\section{REFERENCES}

[1] Winkel, J. "CMLAS Fixed Base Test Pretest Instrumentation Plan Overall Effort Summary", November 2015.

[2] NASA GRC/LMD Modal Test Team "CM/LAS Simulator Modal Test \& Model Correlation Results \& Summary", December 2015.

[3] Akers, J., Bittinger, S., Jones, T., Staab, L., Suárez, V., and Winkel, J. "European Service Module Structural Test Article (E-STA) “Building Block Approach" Modal Test Results." Proceedings of the $87^{\text {th }}$ Shock and Vibration Symposium, New Orleans, LA. October 2016.

[4] NASA GRC/LMD ModalTest Team “CMA Simulator Modal Test\& Model Correlation Results \& Summary”, August 2015.

[5] Winkel, J. “CMA Simulator Free-Free Modal Test Pretest Instrumentation”, July 2015.

[6] NASA/GRC Analys is Team “E-STA Sine Vibration Model Update Log”, February 2017.

[7] Bittinger, S., Winkel, J. “TotalCorrelation Changes in 2017 ESTA”, January 2017. 